\title{
Los muertos siguen 'vivos': velación, bautizo y el matrimonio del difunto.
}

\author{
Estefany San Andrés $\boldsymbol{H}^{1}$
}

\section{RESUMEN}

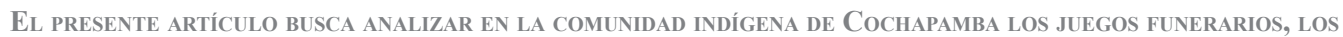
SÍMBOLOS DE LOS RITUALES DEL BAUTIZO Y EL MATRIMONIO DEL DIFUNTO QUE ROMPEN CON EL TABÚ SILENCIOSO Y RESALTAN, MÁS ALLÁ DE LA TRISTEZA, LA ALEGRÍA DE VIVIR; DEVELANDO RELACIONES NO SÓLO SOCIO-CULTURALES Y ESPIRITUALES; SINO TAMBIÉN POLÍTICAS Y LEGALES A TRAVÉS DE LOS COLORES, LAS FORMAS, LAS RISAS Y LÁGRIMAS. ES LA MiSMA VIDA A LA QUe SE CELEbRa, A PROPÓSITO DE LA MUERTE.

Palabras Clave: símbolos y Rituales fúnebres - el bautizo Y el matrimonio del difunto - Juegos y PENITENCIAS FUNERARIAS.

\section{Abstract}

This article presents an ANALYSIS OF FUNERAL games AND THE SYMbology OF BAPTISM AND DECEASED

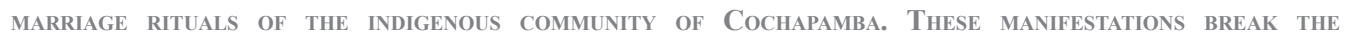
SILENCE-TABOO AND HIGHLIGHT, BEYOND SADNESS, THE JOY OF LIVING; REVEALING NOT ONLY SOCIO-CULTURAL AND SPIRITUAL RELATIONSHIPS BUT ALSO POLITICAL AND LEGAL RELATIONSHIPS THROUgh COLORS, SHAPES, LAUGHTER AND TEARS. IN THIS WAY LIFE IS CELEBRATED EQUALLY IN DEATH.

KEY WORDS: FUNERAL RITUALS AND SYMBOLS - BAPTISM AND MARRIAGE OF THE DEATH - FUNERAL GAMES AND PENANCES.

1 Antropóloga Socio-cultural. Especialización en Derechos, Género e Interculturalidad en Salud. Trabajo actual: Dirección Nacional de Salud Intercultural- Ministerio de Salud Pública del Ecuador (Responsable de la Unidad de Gestión Intercultural).estefy.san.andres@gmail.com 


\section{Introducción}

U n proverbio pigmeo dice "Como la luna, jamás vemos de la muerte su cara oculta". Es precisamente este sentimiento de incertidumbre, de misterio sobre la 'gran desconocida', que hace que el ser humano busque enfrentarla a través de accionares distintos. Y, ¿por qué digo enfrentar? Porque el hombre moderno de occidente, al considerar a la muerte como una enemiga, como una dicotomía de la vida, "practica una estrategia de corte y ocultamiento: silenciar la muerte, maquillar, u ocultar el cadáver, trivializar el morir en su repetición metafórica" (Louis Vincent Thomas, 1991: 58).

Es así como han estado enterrados (antes que los propios difuntos) los temas, conversatorios y análisis fúnebres. Esta evasión negativa, como bien lo expresa el autor antes señalado, convierte al ser humano en un prisionero de la prohibición de la muerte, que no tiene más que huir, escapar. Entonces pensé: se debe romper el silencio investigativo mortuorio.

¿Por qué huir, por qué escapar de algo inevitable? La muerte es un hecho real y concreto que se acerca omnipotente e implacable a todos; es más, lo único seguro que se tiene en la vida es la misma muerte. Pero, sobre todo, es un hecho natural y universal, que trasciende cualquier ámbito económico y cultural. Esta neutralidad que caracteriza a la muerte, hace que su concepto sea multi-vocal y que sea planteada en términos heterogéneos. De esta manera, frente a la naturaleza animal, el ser humano es el único que entierra a sus muertos, que procesa y da un tratamiento a los difuntos, creando así una especificidad cultural dentro de una ley natural.

La domesticación del morir ha sido algo por lo que la ciencia ha luchado eternamente, pero al no hallar un camino certero, el ser humano trató de entenderla y encararla a través de representaciones simbólicas. Como señala Gilbert Durand, figurar al mal, representar a un peligro o simbolizar una angustia es ya una forma de dominarlos; siendo la hipérbole negativa sólo un pretexto para su antítesis (Cfr., 2004). Así, a través de los símbolos se logra superar, de cierta manera, a la muerte biológica, y se crean y recrean rituales donde las prácticas, los cantos, las oraciones e inclusive las tumbas representan lo que no es visible ni palpable en los humanos, sus creencias, valores e ideología: la cultura de la muerte.

Lo planteado en los párrafos precedentes es la base para realizar una defensa de la antropotanatalogía. No sólo la eufemización presente en todo el proceso mortuorio, sino la ritualidad que se desarrolla son parte de la expresión cultural del ser humano que está en constante construcción, al igual que la identidad de las personas. Los contextos históricos y socio-económicos son elementos que modifican estas manifestaciones tanto en el medio urbano como en el rural. Los rituales fúnebres, son entonces formas de comportamiento adaptables a un sinnúmero de variables que provocan una serie de actitudes entre los vivos, pero, al mismo tiempo, pueden representar también una manera de reafirmación y resistencia cultural.

La contradicción, pero a la vez la complementariedad y la inseparabilidad que unen a la vida y a la muerte hacen también de éste un estudio con un tinte antropológico. Aunque la esencialidad de la antropología son los vivos, la antropología de la muerte no solo analiza a los difuntos (su estado, vestimenta, accesorios, etc.), sino que busca, a través de ellos, un camino mediante el cual se pretenda descubrir al vivo; pues, a fin de cuentas, los rituales fúnebres, más allá de un homenaje póstumo, se convierten en un homenaje a la misma vida: es la celebración de la vida la que se conmemora a través de la muerte. Justamente, lo que se persigue son las prácticas y actitudes de los vivos frente a ella. Así como el arte del buen vivir se pretende encontrar también un arte del buen morir. 


\section{Análisis simbólico de rituales fúnebres}

\section{Los dos únicos momentos en los que perdemos la conciencia del tiempo: el orgasmo y la muerte}

A pesar de este corte y rechazo a la muerte, existen todavía lugares donde la 'muerte es vivida' comunitariamente, donde no se esconden, sino que conviven con ella. La comunidad indígena de Cochapamba ${ }^{2}$ refleja precisamente formas o estrategias distintas de acercarse, entender y procesar a la muerte. De ahí que, en los velorios, se evidencien distintos juegos y rituales funerarios que rompen con el tabú silencioso y resaltan, más allá de la tristeza, la alegría de vivir.

En este sentido, el presente trabajo busca analizar los juegos funerarios y los símbolos de los rituales del bautizo y el matrimonio del difunto, aparte de develar las relaciones no sólo socioculturales y espirituales, sino políticas y legales que se esconden a través de los colores, las formas, las risas y las lágrimas.

Son precisamente los símbolos el camino mediante el cual las personas tratamos de responder a la muerte y los rituales fúnebres son la atmósfera perfecta para conjugar tanto las creencias como las incertidumbres. Es por esto que este trabajo no solo expondrá el inter-relacionamiento entre el difunto y sus familiares, sino las lógicas que se ocultan, los roles, y las relaciones familiares y comunitarias que se refuerzan.

En relación a la línea teórica que ha posibilitado el análisis de esta investigación, dentro de la Antropología Simbólica, se encuentran las proposiciones de Victor Turner, que son complementadas con otros autores como Gilbert Durand y Carl Jung. La energía dinámica del símbolo ritual es lo que permite analizar al difunto convertido en un neófito más, desde la perspectiva de Turner de los rituales de paso. Estos rituales en particular presentan tres etapas o períodos por los que debe pasar un neófito para alcanzar nuevamente un estado normal: separación, margen o limen y reintegración. Precisamente son éstas las fases con las que se ha tratado de entender y explicar el proceso ritual fúnebre, considerando al neófito como el difunto, como un viajero-pasajero.

No obstante, al hablar de la interpretación simbólica y de la muerte como un hecho natural, el estudio tendrá en cuenta siempre la incidencia de la naturaleza humana a través de los arquetipos y del inconsciente colectivo de Jung. Es en este sentido, donde las propuestas teóricas de Jung alcanzan una fuerte correspondencia con la línea seguida por Turner. Los arquetipos (formas o imágenes simbólicas heredadas de la naturaleza humana) representan a los contenidos existentes en el inconsciente colectivo; su alta concentración y atención en la estructura y sentido propio de universos simbólicos, alejados de la conciencia occidental tradicional, como el lenguaje de los sueños, las experiencias religiosas y las cosmovisiones orientales, evidencian esta particular característica.

Es importante además señalar que la metodología utilizada en la investigación, tanto en el trabajo de campo (2008- 2009) como en todo el proceso de sistematización de la información, ha tenido un corte cualitativo3.

2 Cochapamba forma parte de la 'COINCA' Comunidades Indígenas de Cangahua (parroquia rural del cantón Cayambe). Más del 90\% de su población se autoidentifica como indígena. Los niveles de migración tanto interna como externa son mínimos y no existe aún gran vinculación con florícolas. De ahí que muchas de sus costumbres y tradiciones permanecen vivas.

3 El artículo presentado a continuación está basado en la Tesis de Disertación de Estefany San Andrés: ¿Una muerte dulce o de sal? Análisis Simbólico Comparativo de los rituales fúnebres entre la ciudad de Cayambe y la Comunidad de Cochapamba; Tesis de Disertación en Antropología; Pontificia Universidad Católica del Ecuador; 2012. 


\section{El poder de la alegría: juegos y penitencias fúnebres}

\section{Los velorios eran para gozar, para reír o para tener miedo}

El objetivo final de la velación es pasar toda la noche con el difunto hasta que éste haya sido procesado y se encuentre listo para ser enterrado. Tanto en la ritualidad indígena como mestiza, el velar al difunto se convierte casi en una obligación social que representa para muchos la despedida de la persona fallecida. Sin embargo, la velación no comprende únicamente este último adiós, sino que es el medio a través del cual se procesa el nuevo estado del difunto y forma parte necesaria también de la aceptación psicológica de la muerte.

Las diferentes actividades que se efectúan en los velorios respectivamente, marcan una gran línea fronteriza que divide a mestizos e indígenas. Las razones principales: la concepción que se tiene sobre la muerte, las distintas formas culturales de afrontar la tristeza que evoca la pérdida de un ser querido y el contexto socioeconómico. De ahí que el ritual fúnebre de la velación, al ser una forma más de expresión cultural, puede provocar desencuentros entre escenarios llenos de llanto y desesperación, versus ambientes donde la risa, los juegos y la diversión son parte primordiales.

En la cosmovisión mestiza, la concepción de la muerte como el paso a una supuesta vida eterna es puesta en tela de duda. El velorio crea un escenario que se sustenta en la pérdida del ser querido y en la idea que se tiene de la muerte como el final que desespera a los que aún están vivos, ya que, a pesar de que todavía existe una fuerte creencia en un aparente paraíso, el debilitamiento de la espiritualidad, de los dogmas y de la iglesia católica es cada vez más fuerte. Por eso, son la tristeza y el desconsuelo los sentimientos que más se hacen evidentes en la velación mestiza. Sin embargo, también se buscan formas de contrarrestar este espacio lúgubre a través de escapes momentáneos de risa; de ahí la popularidad de contar cachos en los velorios.

En los velorios, la alegría y la risa normalmente son desaprobadas socialmente, ya que irían en contra de la formalidad y seriedad que encierran estos rituales mortuorios. Empero, precisamente las actividades lúdicas-alegres son la esencia de los velorios indígenas, ya que esconden un entendimiento totalmente distinto de la muerte, el difunto y la significación de la solidaridad comunitaria.

En los velorios de la comunidad de Cochapamba, no se puede dejar sola a la persona que ha muerto, ya que está pasando por una etapa complicada, por un período especial, donde es muy frágil y se encuentra en desventaja frente a cualquier otro ser. Por este motivo, se debe cuidar del muerto, ya que espíritus o ciertas energías negativas se pueden apoderar de él. Todas estas características del difunto son compartidas por los neófitos en el período liminal en los ritos de pasaje; su similitud es tan fuerte que incluso el mismo Turner compara el tratamiento del neófito o pasajero con el procesamiento de los cadáveres. Además, se subraya la inestabilidad e imprecisión de este estado:

Son comparados o tratados como embriones, no están ni vivos ni muertos, por un lado; mientras que por otro están tanto vivos como muertos. Su condición es de ambigüedad y paradoja...ellos son hombres desnudos, desposeídos, atributos de invisibilidad estructural, ambigüedad y neutralidad... esta coincidencia de procesos y nociones opuestos, caracteriza la peculiar unidad de lo liminal: aquello que no es ni esto ni lo otro, sin embargo, es ambos (1973: 58-60).

Precisamente, los asistentes son una especie de protectores, cuyo apoyo se ve reflejado en ese acompañar permanente; sin embargo, si sucumben ante el sueño, la falta de conciencia debilita este poder de los vivos sobre los muertos y deja expuesto al cadáver ante fuerzas no deseadas. De ahí, la infinidad de historias y juegos presentes en los velorios que brindan un espacio para transmitir la tradición oral, y reafirmar la identidad y cultura del fallecido, de sus familiares y amigos. 
Aunque a continuación se describirán los juegos y penitencias como parte esencial de los velorios, es importante mencionar que existen varios momentos de solemnidad y llanto cantado que permiten tener un deshago emocional y hacer un homenaje a la persona fallecida.

Los familiares no juegan, se dedican a atender a los acompañantes y especialmente la primera noche "sí lloran bastante y pasan conversando que por qué ha muerto. Todos participan en la noche, la mayoría son jóvenes que van para jugar, pero más las otras noches, la última especialmente" (Hilda y Elsa). Así, el llanto en este ritual fúnebre se convierte en un canto como describe a continuación Aguiló:

Hay un fondo ancestral común que une al canto y al llanto hasta convertirlos en rito. Cuando el llanto ritual se produce en el caso de muerte, el ritmo de ese llanto adquiere los tonos de un verdadero canto...El llanto discursivo, propio del velorio, no sólo se acerca al ritmo musical del canto, sino que como éste tiene una narrativa específica por la que se lloran-cantan los recuerdos y las hazañas de la persona querida...el llanto y la risa tienen un marco ritual, que sin producir una falsa afectación, permiten un control social de los sentimientos personales o colectivos (Aguiló, 1985: 321).

En este sentido el sacerdote del lugar afirma que el velorio de Cocahapamba es muy diferente al de la ciudad en función del llanto, ya que el lloro es totalmente distinto, es cantado. Inclusive existen personas encargadas de hacer llorar: los ancianos. Ellos sacan a la luz toda la memoria sobre el difunto: ¿quién era, qué hacía, cómo crecieron juntos, cómo sufrieron, qué hacía de niño? Entonces cada persona va llorando y manifiesta dónde conoció al fallecido, cuáles eran sus principales características, sus cualidades, etc. Así, todos los acompañantes mientras lloran, tienen que narrar su propia convivencia con el difunto: "Son relatos muy bonitos que se dan en el velorio y en el traslado al cementerio". Además, el padre afirma que se relata lo que esa persona ha significado en la vida del narrador y lo que se quiere y se anhela para él. Los ancianos cumplen un rol muy importante, al representar la historia y la memoria. El hacer memoria y compartir las convivencias personales es parte del proceso de aceptación de la muerte y del lazo que cada acompañante del velorio mantiene con el fallecido.

Aparte de este llanto -canto ritual- y de los momentos donde se hace rezar al difunto, en las noches especialmente no hay espacio para el silencio y menos aún para el sueño. Sí, aunque no parezca ser cierto, los velorios son escenarios llenos de risa y diversión, en donde se cuentan historias antiguas y se realizan juegos, cuya función es entretener a los asistentes para que no se duerman y puedan acompañar toda la noche al difunto.

Sin embargo, el 'jugar' tiene también otra finalidad. Las actividades cotidianas de las comunidades indígenas son adaptadas, de cierta manera, a los juegos y a los símbolos presentes en ellas. Estas actividades lúdicas reflejan entonces no sólo la realidad económica, sino ambiental y social local. Por ejemplo, uno de los juegos más típicos es el de la cebolla ${ }^{4}$ que consiste en la representación cómica de la producción, venta y comercialización de esta hortaliza, al ser una de las principales actividades agrícolas a las que se dedica la población. También está el juego del molino .

Existen otros juegos que no sólo describen la cotidianidad y la problemática que se vive en la comunidad, sino que hacen alusión tanto a la fauna, flora y al medio ambiente local, así como a las formas de supervivencia y adaptación al mismo. Muchos de estos juegos presentan un

4 Se elige un comprador, un vendedor, las amarradoras y alguien que simbolice a la raíz de la tierra. Los demás participantes representan a las cebollas, quienes deben ser divididos según los distintos tipos de esta hortaliza en relación al aspecto físico de cada participante. Luego se representa todo el proceso de producción, venta y comercialización. Para ello se jala, se bota agua a las 'cebollas' o se usa un palo para aflojarlas. Una vez que son sacadas de la tierra, se las amarra en pequeños montones y se las apila una sobre otra.

5 "la gente simula que está moliendo para hacer la comida y entonces dicen ahora vamos a moler cebolla y tienen que moler cebolla, ahora vamos a moler maíz y van a moler maíz, y una de esas dice ve se está atrancando y botan el agua a cualquier persona". 
aspecto que hace aún más sugestivas a las actividades lúdicas que se desarrollan en estos rituales fúnebres: las características humanas que se otorgan a los animales o una posible animalidad presente en los humanos.

Fuera de su significación arquetípica, el animal es susceptible de ser sobredeterminado por características que no se vinculan directamente con la animalidad...provoca cierta polivalencia semántica... se trata de buscar el sentido de lo abstracto espontáneo representado por el animal (Ibíd., 2004: 74).

En este caso, el tiempo sagrado de la velación del difunto permite que se borren las barreras entre la humanidad y los animales, y se pueda resaltar, por un lado, las características físicas y funcionales (formas, colores del curiquingue, utilidad del conejo) como enseñanzas y aprendizaje de su mundo cultural y ambiental; y por otro, las aptitudes o capacidades positivas de los animales como metáforas aplicables al contexto humano (la rapidez del conejo, la astucia del perro o la fuerza del toro). Este análisis se refleja en el juego de la caza del conejo, (otra acción popular en Cochapamba), en donde una persona debe representar al cazador o al perro; el curiquingue, el borreguito, los gallos ${ }^{6}$ o los toros.

Existen otro tipo de juegos en los velorios que enfatizan la naturaleza (sus peligros) y las actividades agrícolas comunes, en donde inclusive las personas se transforman en agua, en plantas o vegetales como las cebollas o las habas. Esto denota además, el alto grado de animismo presente en este escenario rural, donde todo y todos (animales y plantas) son seres llenos de vida. Ejemplo de esto, es el juego del cruce del río o el de habas peley.

Otro objetivo esencial de estas actividades es que el difunto 'se vaya feliz'. De ahí que los juegos deben también entretener al muerto: "jugamos porque el alma no puede irse tan triste, eso es malo, por eso no hay que llorar mucho". En este contexto, la visión de solidaridad se presenta de otra manera, no sólo con el mismo muerto sino con su familia, ya que "los parientes ya están bien tristes, llorando; entonces ¡cómo nosotros vamos a llorar más!, nosotros debemos apoyarles". De ahí que la característica principal de los juegos sea la gracia y el humor.

Por otro lado, otra actividad fundamental en los velorios, a parte de los juegos, son las penitencias graciosas que se realizan, especialmente con los participantes perdedores. Algunas se detallan a continuación: traer a una mosca preñada (grande que sea barrigona) con los dientes; mandar a gritar habas peley (todos tienen que pellizcarle como pelar las habas); pasar el hilo en la aguja, pero sentado en una botella; meter un pucho de tabaco encendido en la botella, traer un pilche de chicha con la boca, ir al cementerio, darle un beso al difunto.

Existe otra clase de penitencias que incluyen el gritar en público o el 'llorar cantando': "deben decir por qué me vas dejando, que se ha muerto y ha quedado la olla y la comida de él"; "tenía que gritar, tres veces vecinos por qué no han venido al velorio como que ustedeska no van a morir que no han venido"; "deben salir a la calle y gritar quiero casarme y no hallo con quién, con la Pocha me parece bien. Pero es la vergüenza lo que tiene que pasar porque la Pocha era una mujer bien fea que siempre andaba descalza".

Se hacen también diferente bromas a las personas que se han quedado dormidas ya que "está prohibido dormir en los velorios": "cuando se duermen se amarran las chalinas, les queman el pelo, les pintan la cara con carbón, ahora que ya van con zapatos les amarran los cordones entre varios para que cuando se levanten se caigan", "les pasa por la cara en forma de cruz el carbón; saben amarrar entre las personas con alambres para que no se puedan levantar y el uno y el otro se jalan".

De esta forma, la intención del acompañamiento en el velorio es primordialmente el provocar alegría como una forma de enfrentar a la muerte tanto para el difunto como para sus familiares;

6 "les amarran las manos a dos como si fueran dos gallos y de ahí se pelean y queman los pelos con la vela que están velando". 
y la intención de los juegos es permitir la creación de espacios donde la muerte sea procesada también a través de la alegría; de ahí la importancia del acompañamiento social en los velorios para reafirmar la cohesión y las relaciones comunitarias. En este sentido, estos rituales fúnebres pretenderían 'descubrir al vivo'; pues, a fin de cuentas, es la misma celebración de la vida la que se conmemora a través de la muerte.

\title{
Niños difuntos y el bautizo, solteros difuntos y el matrimonio
}

\author{
El fondo del lago se vuelve el cielo, los peces son sus pájaros
}

Gilbert Durand

A diferencia del mundo mestizo, la ideología indígena que se tiene sobre la muerte está en relación a la edad del difunto e inclusive en relación a su estado civil. Es así como se presencian rituales fúnebres distintos entre los velorios de niños, de personas adultas y de casados o solteros. A continuación se describen varias de las actividades efectuadas en estos velorios, los elementos usados y sus posibles significaciones.

\section{El bautizo del difunto}

Si el velorio de una persona indígena adulta incluye varios juegos y diversión, los ritos que se presencian en la velación de un niño son aún más alegres. Esto se debe a que el niño es considerado como un ángel por su pureza e inocencia y, al no tener 'pecados', va directamente al cielo, representando para la familia un medio de intersección entre Dios y ese espacio sagrado, y las personas vivas terrenales.

En este caso, se reitera la idea de la reciprocidad fúnebre como la relación constante que se tiene con los difuntos como intercesores con Dios, como vínculo de lo terrenal y lo divino. Este hecho marca las relaciones de intercambio entre muertos y vivos que, según Emilia Ferraro, son parte del repertorio de la reciprocidad. Siendo así, se establecen especiales y profundas relaciones que perdurarán más allá de la muerte, al igual que las que se crean entre los neófitos e instructores en los ritos de transición.

Esta cercanía a Dios ubica al niño difunto casi en un nivel de santidad que se muestra en un altar construido por sus familiares. El niño es colocado en el centro del mismo en una especie de cuna que está formada tradicionalmente con carrizos y con chalinas azules. Las chalinas azules son la analogía del símbolo del cielo, por el color y su forma ascendente. Aunque la idea del cielo o paraíso no es común en la cosmovisión indígena, en este caso se cree firmemente en ella, ya que el niño no podría continuar con su vida en otro espacio porque no es una persona independiente, necesita del cuidado de sus padres o abuelos que siguen en la Tierra. De esta forma, en contraste con el mundo al cual los adultos van después de muertos y continúan con su vida como lo hacían cuando estaban vivos, los niños van al cielo. Así, este altar elevado vendría a representar a una 'montaña sagrada' que según Gilbert Durand estaría consagrada al culto al cielo, al soportar un fuego encendido o faro (las velas), que simbolizaría al pájaro de la aurora (Espíritu Santo católico), en espera de la unión divina (niño-ángel), (Cfr., 2004). Resaltan en el altar, la cruz y la corona de flores haciendo alusión nuevamente a la muerte y resurrección de Jesús. Por otro lado, la ropa del difunto es un elemento que también debe ser procesado, ya que forma parte esencial de la persona fallecida. De ahí que también esté presente en la velación?.

7 En el caso de la velación de un adulto, la ropa tendrá una significación especial, y formará parte de un ritual postmortem: el takshay (el lavado, la limpieza). 
Esta creencia del niño como ángel y de que su alma es pura sustenta, de alguna manera, el sacramento del bautizo católico. Dado que el niño irá al cielo, es imprescindible que éste sea bautizado porque es la señal que representa ser parte de la Iglesia y haber sido purificado: "se debe bautizar al niño, como hacen los catequistas o animadores. Se tiene que cumplir con este requerimiento católico" (Estudiantes del 'Colegio Intercultural Dolores Cacuango'). Por este motivo, si el infante no ha sido bautizado, se debe realizar todo el ritual de esta ceremonia durante el velorio, implicando este hecho también la elección y presencia de padrinos o madrinas: "Si es niño el que no está bautizado, coge padrinos y el padrino da el ataúd y debe dar toda la ropa, los padrinos gastan eso: la ropa, el ataúd, las espermas" (Hilda y Elsa).

De la cita se desprende un factor interesante dentro del bautizo, ya que éste no es solamente una manera espiritual de garantizar el cielo para el difunto al cumplir un dogma católico, sino que implica también lógicas económicas internas. El elegir padrinos, aunque el niño esté muerto, es una forma de contribuir económicamente con todos los gastos que implica esta situación y, se evidencia así, la importancia de las relaciones de compadrazgo existentes en las comunidades indígenas como una estrategia de apoyo comunal. En este caso es más que una obligación social, no legal, que está presente siempre, porque representa una relación de solidaridad y reciprocidad, al mismo tiempo.

De igual modo, el bautizo representa también una forma de renacimiento y tiene la connotación de limpieza y pureza, siendo el principal elemento utilizado el agua. Esta idea es esencial, si se cree firmemente en la muerte no como un fin, sino como una continuación. Este elemento se transforma en agua celestial ya que "el agua dobla, desdobla, redobla al mundo y los seres, el reflejo es factor de redoblamiento, el fondo del lago se vuelve el cielo, los peces son sus pájaros" (Gilbert Durand, 2004: 216). Siendo así, los símbolos ascensionales persiguen siempre la pureza, en este caso el valor inconsciente otorgado al agua es precisamente purificatorio (tanto por la blancura como por el frío), ya que 'despierta al organismo', hace vivir más allá de lo físico.

El ambiente que se vive en los velorios infantiles es bastante festivo "incluso en algunas comunidades los papás y los padrinos salen de la casa bailando con el cadáver del niño". Los juegos en las noches son cada vez más intensos y parte primordial de estas tradiciones fúnebres. En ningún momento se da el pésame y la chicha es parte primordial de todo el proceso ritual, donde cada persona tiene que repartir esta bebida por lo menos una vez en un punto del velorio. Por otro lado, en la velación, se delinea también una especie de división espacial entre hombres y mujeres y, del mismo modo que en el cementerio, el rol masculino está más asociado a las bebidas alcohólicas (aunque la chicha es repartida por mujeres también). Finalmente, todo el escenario creado es propicio también para que se fortalezcan relaciones sociales e incluso amorosas-sentimentales, como se aprecia en la cita a continuación:

Los visitantes se ubican en el espacio de una manera determinada. Por lo general están los hombres juntos en las bancas de madera, las mujeres, la mayoría sentadas en las esteras y los niños en la parte posterior de la sala. Los hombres, especialmente los jóvenes, toman entre ellos puntas, aparte de la chicha que les sirven. Hombres, mujeres y niños llevan prendas de colores. En ningún momento se presencia llanto ni tristeza ${ }^{8}$, más bien varios de los acompañantes pasan sonriendo y haciendo bromas; hasta algunos incluso coquetean y crean o recrean nuevas relaciones sentimentales.

Más allá de todo el simbolismo indígena de la muerte de un niño, su ascensión directa al cielo y su alma angelical, los rituales fúnebres y la forma festiva cómo se los trata podrían reflejar una estrategia de adaptación a las condiciones de vida reales de la población indígena. Especialmente en el pasado, la tasa de mortalidad infantil era bastante alta, al igual que el número de hijos que

8 Esto no quiere decir que los padres o hermanos del niño no estén tristes y se contenten de la pérdida de su ser querido; por supuesto ellos también sienten dolor. De ahí, que los parientes más cercanos no se integran en los juegos, pero sí disfrutan de estas actividades. 
se tenía en cada matrimonio; de ahí que la pérdida de un niño no era tan inusual. Este ritual sería entonces una forma de respuesta cultural a un hecho que se convirtió en un elemento casi natural.

\section{El matrimonio del difunto}

Otra condición que marca el tipo de ritual a llevarse a cabo en un velorio indígena es el estado civil del difunto. El ser casado o soltero es la pregunta clave. Si la persona que ha fallecido es viuda o casada, no existen peculiaridades a más de las ya descritas. Sin embargo, por lo general, en la cosmovisión indígena la soltería no es socialmente aceptada en los vivos (el matrimonio es siempre la visión ideal), y menos aún es admitida en un/a difunto/a, por lo que requiere de un tratamiento obligatorio: el matrimonio:

Le sabían hacer casar al muerto. Cuando el hombre o la mujer han sido solteros, la familia ha sabido buscar un novio o novia y le hacen casar después de muerto o ya yendo a morir. Pero no les casa 'taita cura', sino que hacen un juramento entre ellos. Los papás les hacen jurar, le hacen juramento de mano porque no hay ninguna ley más fuerte que el último deseo del difunto... (Habitante de Cangahua).

Como se expresa en la cita, parte esencial del ritual fúnebre en la velación, es la realización de una especie de simulación de la ceremonia matrimonial. Al igual que una boda normal, se deben elegir a los padrinos, alguien que reemplace al sacerdote (que por lo general es el rezador ${ }^{9}$ al ser la persona más ligada al mundo católico), y por supuesto un/a novio/a: "Ahí se hace uno de cura, de sacristán; se eligen padrinos y madrinas para que les hagan casar. No va el cura de verdad, las madrinas tienen que estar al lado, el padrino debe dar la ropa". En el caso de que el/la difunto/a haya tenido un/a novio/a anteriormente, se debe pedir a esta persona que acepte casarse con quien ha fallecido. No obstante, en varios casos, los/as novios/as se niegan a hacerlo dado la connotación tan fuerte que tiene el casarse con un difunto: "Si ha tenido enamorado o enamorada se le hace casar, solo si quiere y no tiene miedo porque el difunto tiene la mano fría. Si no hacen casar, casa con diablo, con chiva, en ese infierno".

Pero si no ha tenido novio/a o ellos no han aceptado casarse con la persona fallecida, la solución es buscar otro/a chico/a para que la boda pueda realizarse y convencerlo/a a él/ella o a su familia ofreciendo una recompensa o algo a cambio.

Varias pueden ser las recompensas que se ofrecen para el novio o la novia y sus familiares. La comida es el primer elemento del cual el elegido y sus parientes se benefician en mayor escala; también muchas de las pertenencias del difunto (especialmente su ropa) pasan a ser de los padres o familiares cercanos del novio o novia, y esta persona adquiere algún bien especial o herencias de tierras o animales del fallecido: "La novia o el novio si es que casa tiene que coger tierra, la herencia que toca del difunto"; "...bueno depende de la voluntad de los familiares, a veces dan ropa del fallecido para que se pongan o para que vendan o hacen algún regalo" (Ricardo Ulcuango).

De los testimonios presentados se podría también afirmar que este rito fúnebre es una táctica para dar respuesta al problema de herencias que puede existir cuando un soltero muere y así, evitar cualquier problema social que esto pueda producir, ya que los testamentos no son habituales en las poblaciones indígenas. Nuevamente se aprecia cómo el ritual mortuorio se adapta también a las necesidades que surgen de la realidad y la cotidianidad.

El casamiento no sólo presenta la cosmovisión que las comunidades indígenas tienen sobre la muerte y sus miedos, sino que revela también un aspecto económico oculto atrás de este rito. De igual forma que sucede con el rol que cumplen los padrinos en el bautizo de los niños difuntos,

9 El rezador es una persona, por lo general, indígena que es cercana a la Iglesia Católica o conoce las oraciones (Padre Nuestro y Avemaría). Él es el punto de unión con la ritualidad religiosa formal y los sacramentos católicos, remplaza al sacerdote. 
especialmente, los 'viudos' y madrinas o padrinos deberán apoyar y contribuir con comida o con cualquier gasto en el entierro. Este hecho reemplaza a la importante función que cumple el esposo o esposa cuando su cónyuge ha fallecido, ya que el soltero, de cierta forma, se encuentra solo. En este sentido, el no estar casado teniendo ya una edad adulta no es muy común en el mundo indígena, debido a que la familia y los hijos representan un apoyo y complementariedad del ser individual. Ya que la muerte es el paso a otro espacio, en donde se continúa con la misma vida, si el difunto no se casa, permanecerá soltero por siempre.

Si bien es cierto que la cosmovisión indígena es muy diferente en varios aspectos y, aunque no existe un rechazo latente hacia el cadáver como en el mundo mestizo, el hecho de casarse con un difunto no es una tarea fácil para nadie porque la idea de separación de la persona fallecida es universal, y precisamente lo que busca el matrimonio es una unión, una alianza con el difunto.

Le pueden hacer casar con cualquier chica, no importa que no haya sido la enamorada, saben rogarle y le ofrecen algo para que acepte... la familia busca el novio para que el muerto no se vaya a casar con chivas o chivos o alguien que se arriesgue, o sea como 'demonios' en la otra vida... La viuda o el viudo ayudan en el entierro como viuda o viudo normal y si el muerto tiene herencia o animales, eso pasa a la mamá o a la familia del viudo o la viuda...el viudo hereda los bienes. Chistoso es no vea..." (Dueño de tienda naturista, Cangahua).

El proceso del matrimonio tiene tres elementos esenciales: el coger la mano al difunto, la puesta de los anillos y la bendición del rezador: "Si es un soltero igual que a un vivo le casan, le hacen coger la mano del muerto con la del vivo, le dan el anillo los padrinos y le dan la bendición, con anillos, con todo como es legalmente" (Mercedes Morales). El material de los anillos es trascendental, ya que es la simbolización directa de la unión efectuada. Por ello, según Ricardo Ulcuango, los aros no podrán ser de tierra o de barro ya que este material se deshace (del mismo modo momentáneo que la alianza matrimonial podría concluir), sino de hilo ya que “es más difícil que se descomponga con el tiempo y dura más". Así, el anillo (la unión marital) simboliza inmortalidad incluso frente al mismo cuerpo que también será descompuesto.

El siguiente testimonio resume lo dicho sobre esta tradición y presenta los sentimientos y la experiencia vivida por María, quien fue la novia de un difunto hace dieciséis años:

Cuando yo tenía unos dieciséis años vinieron los papás (del difunto) a rogar, solamente era conocida, yo no era enamorada de él. Me dijeron cuando muera casa con chivo, déme palabreando. Al principio estaba miedosa, después ya acepté, estaba envuelta con una chalina blanca, me fui a la casa donde le estaban velando, la tercera noche antes de ir a enterrarle, en la tarde me hicieron casar... El rezador hace casar, un ratito hay que estar agarrados las manos... estaba nerviosa, con miedo, no dije ninguna palabra. ¡Qué miedo! No le doy beso ni nada, ahí me hubiera cogido un desmayo... (Pisanvilla- Cangahua, 2008).

\section{La eufemización del casamiento con el chivo}

De las citas arriba expuestas, se vislumbran varios aspectos de suma importancia para el análisis del simbolismo fúnebre en este contexto rural. Por un lado, el frío es relacionado a la muerte. El miedo presente en los familiares y amigos es que si el difunto se va soltero al otro mundo podría casarse con 'el chivo o la chiva', eufemización directa del diablo o demonio, que estaría relacionada con "la creencia universal en los poderes maléficos ligada a la valorización negativa del simbolismo animal, muchos demonios son espíritus desencarnados de animales" (Gilbert Durand, 2004: 87).

El imaginario común del diablo tiene cachos o cuernos al igual que el chivo, pero, ¿qué asociación exactamente existe entre estos dos seres? Es interesante notar que, aunque el pueblo indígena no cree en el infierno, en este caso es fuerte la idea de este lugar, de sus peligros y de Satanás, denotando así la influencia de la iglesia católica en la cosmovisión indígena. Además, 
las características físicas del chivo y su aullido hacen posible una analogía con seres demoníacos que están ligados a lo velludo, el pelo negro o la barba oscura. No obstante, el chivo vendría a ser no solo una adaptación informal de la cosmovisión católica del mal (omnipotencia y agresividad), sino que también haría alusión a una simbolización de la potencia viril en este contexto del matrimonio como plantea Louis Thomas (1991,147-148): "La anatomía animal, el cuerno, imputrescible y cuya forma oblonga es directamente sugestiva a la potencia viril, porque son los animales machos los que llevan los cuernos, la omnipotencia se une a la agresividad, arma poderosa, cabeza política o religiosa".

Sin embargo, contradictoriamente a lo anteriormente planteado, otro tema bastante sugestivo es la posibilidad de la feminización del mal (la chiva) que en la religión católica no es posible, ya que el mal, al igual que el bien, son conceptos con fuertes connotaciones de poder que 'no están al alcance del género femenino'. Es así como una mujer no puede representar a Dios ni a su hijo (aunque no se lo conozca, la imagen del Todopoderoso siempre es masculina), tampoco a las autoridades de la Iglesia (el Papa, los sacerdotes. etc.). En esta misma línea, la figura paterna es la que se liga al poder, así éste sea negativo. No existen mujeres diablas. Sin embargo, en este contexto rural, el demonio debe ser femenino en el caso de que el difunto sea masculino.

Este rito denota, además, la creencia en la presencia del mal y del diablo en la otra vida, donde existe la posibilidad que los seres humanos inclusive se puedan casar con él o ella. Pero, ¿cómo un ser terrenal se puede casar con un demonio? Es justamente la muerte el hecho que permite que la persona pase a un estado diferente y pueda formar una alianza entre lo mortal y un poder sobrehumano. De esta manera, este rito vendría a ser, como ya se planteó, una especie de acoplamiento, de adaptación informal del sacramento católico del matrimonio (al igual que en el caso del bautizo del difunto) como parte de una religiosidad popular. Además, reflejaría enseñanzas sociales y reafirmaría creencias como las que atribuyen al ser soltero un signo de debilidad, y a su vez, el tener hijos, una familia, como un aspecto positivo, parte de la organicidad económica de la familia.

\section{El matrimonio con la paloma: el eros sublimado}

Hay ciertos casos en los que no se logra conseguir ninguna novia o novio para el difunto soltero, aunque estén en juego herencias y beneficios económicos. En este caso, la personificación demoníaca representada por el chivo/a, es contrarrestada con otro animal: la paloma:

Y si nadie ha querido casarse, saben hacer casar con paloma. Llevan dos palomas blancas, tienen que ser sin mancha y así cogiendo el nombre del difunto tienen que decir y poner nombre de una chica a la paloma. No les matan a las palomas, al final, las palomas vivas deben ponerle en el ataúd y se debe elegir padrinos también... (Elsa e Hilda).

¿Cuáles son las características que se atribuye a esta ave para que sea capaz de contrarrestar al poder maligno del chivo? Precisamente la elección de la paloma blanca, sin mancha, refuerza las características físicas y simbólicas contrastantes con el animal que representa al demonio: "pájaro puro, la misma pureza en sí, la herramienta ascensional es el ala, el pájaro es desanimalizado, en ella convergen el ala, la elevación, la flecha, la pureza y la luz...es el proceso de angelización del pájaro, símbolo del eros sublimado" (Gilbert Durand, 2004: 141-143). De esta forma, la paloma como símbolo ascensional representa al cielo, al aire, al vuelo; en contradicción con la terrenalidad del chivo y especialmente de la culebra que desde el génesis de la vida simboliza al demonio.

Por otro lado, más allá de esta oposición planteada cielo/tierra, sagrado/profano, pureza/ pecado, este símbolo esconde una connotación sexual que se evidencia claramente al ser el símbolo dominante del ritual de matrimonio. No sólo el autor antes señalado ya define a la paloma como un eros sublimado (porque existe una confusión entre la erección y la elevación, 
como símbolo primitivo del padre, de la virilidad y su potencia), sino que la explicación psicoanalítica desarrollada por Jung sostiene que el símbolo animal sería la figura de la líbido sexual, basándose en que el pájaro, el pez, la serpiente eran símbolos fálicos entre los antiguos, al igual que el toro, el chivo, el carnero y el jabalí (Gilbert Durand, 2004).

En este punto, la simbolización sexual une tanto el chivo como a la paloma; sin embargo, la diferencia es que la sexualidad de la paloma es sublimada por la pureza celestial y, en este caso concreto, por la santidad del sacramento del matrimonio, ya que las relaciones sexuales son social y 'legalmente' aprobadas a partir de la noche de bodas. Además, otro aspecto que diviniza a la paloma es su representación del cuerpo físico de Cristo, su resurrección a través del Espíritu Santo, una vez que muere. En el caso de la serpiente, es aún más explícita su evocación sexual, al recordar su representación del mal al hacer pecar a Adán y Eva cuando aún eran vírgenes, (al igual que el difunto soltero), momento después del cual se inicia el concepto de sexualidad y tienen vergüenza de estar desnudos. La siguiente pintura reúne, de cierto modo, las interpretaciones simbólicas antes analizadas: la paloma, el espíritu santo, el ángel, el agua, el cielo y la tierra, lo sagrado y lo profano, el renacimiento (a través del bautizo) y, por supuesto, el eros sublimado. En la Figura 1, se puede apreciar la alusión fálica del brazo izquierdo de Jesús.

\section{Algunas conclusiones}

No es otra vida, es la misma vida pero en otro tiempo

No existe un solo camino para la interpretación de los símbolos rituales. La visión del símbolo junguiana, no solamente como una expresión cultural, sino como una mediación entre el orden social y un cierto inconsciente colectivo, permitió descifrar mucha de la iconografía presente a través de la teoría de los arquetipos y, además, fue de vital importancia, para encontrar un camino común entre la simbología mestiza e indígena, rompiendo ciertas fronteras simbólicas imaginarias.

El carácter de ambigüedad de la muerte, sumado a la universalidad de este proceso y al desconocimiento que se tiene sobre ella, crea en el ser humano un sentimiento de impotencia que es reconfortado a través de símbolos y ritos polisémicos basados en una cosmovisión fúnebre. La muerte evoca sentimientos entremezclados, únicos, que manifiestan esa sublevación del ser humano frente a la naturaleza, donde sólo universos simbólicos persisten en el 'más allá'.

La religiosidad popular indígena logra dominar a los dogmas y sacramentos católicos a través de la burla y la risa. Definitivamente no existe un sincretismo religioso donde primen los preceptos católicos, sino una ideología andina que incluye en sus rituales o adapta a su mundo ecológico-cultural versiones 'informales' del catolicismo.

El proceso ritual fúnebre indígena no solo refleja su cosmovisión, sino que se ven implicados varios factores como relaciones de compadrazgo, organicidad económica, reafirmación de relaciones del grupo, normas sociales e inclusive relaciones de género. Es un medio a través del cual se refuerza la identidad cultural y, sobretodo, se experimenta y se supera a la muerte comunitariamente. Es el mismo accionar de la vida el que cobra fuerza, a propósito de la muerte. 


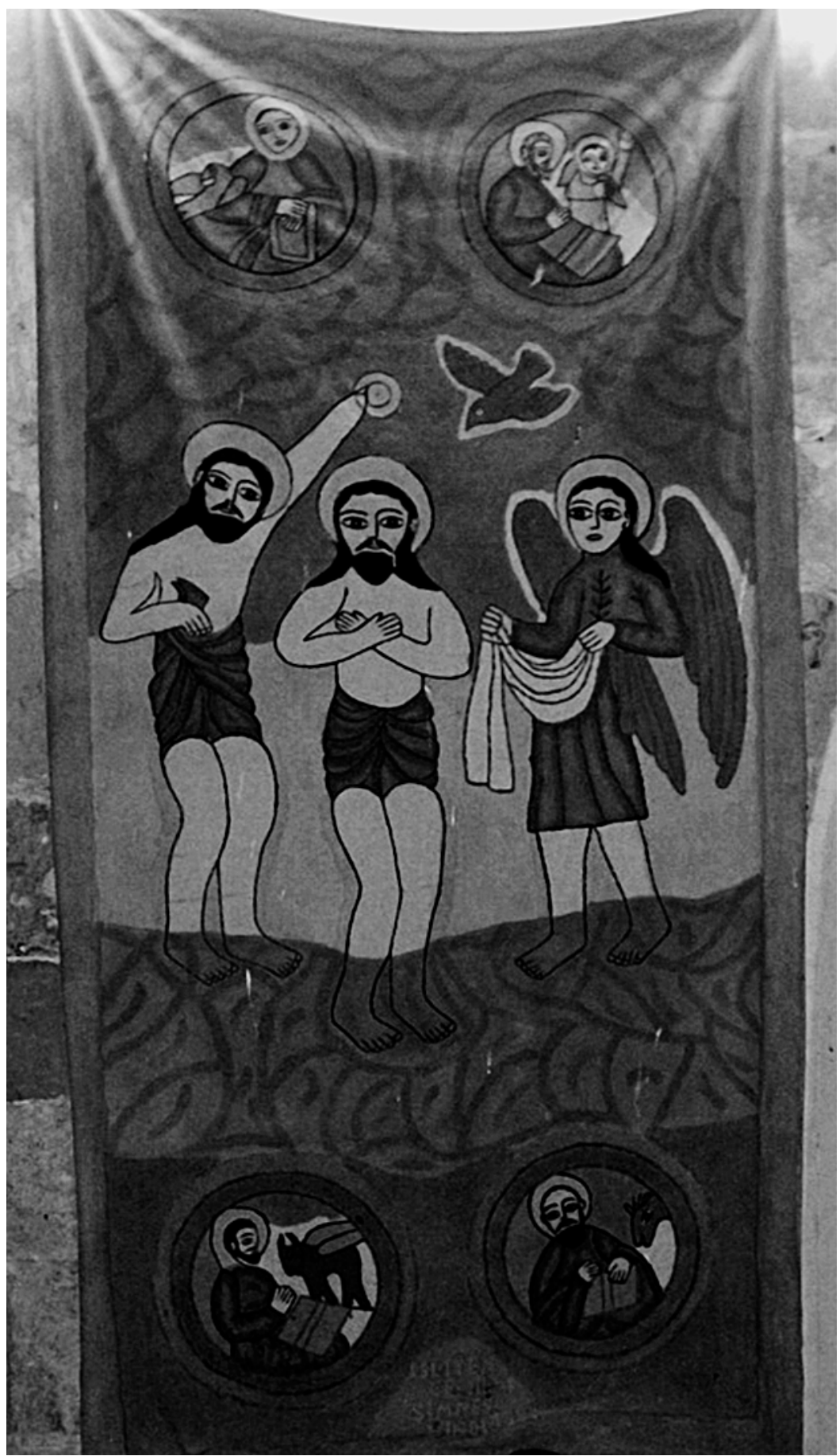

Figura 1. 'Bautizo de Jesús', ubicado en el Monasterio católico en Mardin-Turquía. Pintura EN TELA/Autor DESCONOCido. 


\section{Bibliografía}

Aguiló, Federico.1985. El hombre del Chimborazo. Ecuador: Colección Mundo Andino.

Durand, Gilbert. 2004. Las estructuras antropológicas del imaginario. España: Fondo de Cultura Económica. Elias, Norbert. 1988. Teoría del símbolo: un ensayo de antropología cultural, Edicions 62, España.

Moya, Ruth. 1981. Simbolismo y Ritual en el Ecuador Andino. Otavalo: Instituto Otavaleño de Antropología. Jung, Carl. 1964. El Hombre y sus Símbolos. Barcelona: Editorial Paidós,

Jung, Carl. 1993. Símbolos de Transformación. Buenos Aires-Argentina: Paidós.

Jung, Carl. 1995. El hombre y sus símbolo [et al.]. Buenos Aires: Paidós.

Thomas Louis, Vincent. 1983. Antropología de la Muerte. México: Fondo de Cultura.

Thomas Louis, Vincent. 1991. La muerte: Una lectura cultural. México: Fondo de Cultura.

Turner, Víctor. 1967. La Selva de los Símbolos. Madrid-España: Siglo Veintiuno.

Turner, Víctor. 1967. Aspectos del ritual Ndembu. Madrid: Siglo XXI.

Turner, Víctor. 1973. Simbolismo y Ritual, Pontificia Universidad Católica (Serie de Antropología), Lima-Perú.

Turner, Victor. 1985. On the edge of the bush: anthropology as experience, Anthropology of form and meaning,

Tucson, University of Arizona Pressi. 